\title{
Study on the Influences of Reduction Temperature on Nickel-Yttria-Stabilized Zirconia Solid Oxide Fuel Cell Anode Using Nickel Oxide-Film Electrode
}

\author{
Zhenjun Jiao $^{a, b}, \mathrm{Ai} \mathrm{Ueno}^{c}$, Yuji Suzuki ${ }^{c}$, Naoki Shikazono ${ }^{a, b}$ \\ a. Institute of Industrial Science, the University of Tokyo 4-6-1 Komaba, Meguro-ku, Tokyo \\ 153-8505, Japan \\ b.CREST, JST, 4-6-1 Komaba, Meguro-ku, Tokyo 153-8505, Japan \\ c.Department of Mechanical Engineering, The University of Tokyo, 7-3-1 Hongo, \\ Bunkyo-ku, Tokyo 113-8656, Japan
}

\begin{abstract}
In this study, the reduction processes of nickel oxide at different temperatures were investigated using nickel-film anode to study the influences of reduction temperature on the initial performances and stability of nickel-yttria-stabilized zirconia anode. Compared to conventional nickel-yttria-stabilized zirconia composite cermet anode, nickel-film anode has the advantage of direct observation at nickel-yttria-stabilized zirconia interface. The microstructural changes were characterized by scanning electron microscopy. The reduction process of nickel oxide is considered to be determined by the competition between the mechanisms of volume reduction in nickel oxide-nickel reaction and nickel sintering. Electrochemical impedance spectroscopy was applied to analyze the time variation of the nickel-film anode electrochemical characteristics. The anode performances and microstructural changes before and after 100 hours discharging and open circuit operations were analyzed. The degradation of nickel-film anode is considered to be determined by the co-effect between the nickel sintering and the change of nickel-yttria-stabilized zirconia interface bonding condition.
\end{abstract}

Keywords: SOFC, Reduction, Ni-film, NiO-film

Email address: zhenjun@iis.u-tokyo.ac.jp (Naoki Shikazono ${ }^{a, b}$ )

Preprint submitted to Elsevier

August 4, 2016

(C) 2016. This manuscript version is made available under the Elsevier user license http://www.elsevier.com/open-access/userlicense/1.0/ 


\section{Introduction}

With high energy conversion efficiency and fuel flexibility, solid oxide fuel cell (SOFC) has been attracting more and more attentions in the last few decades $[1,2]$. It is well known that nickel (Ni) coarsening, which results in the decrease of active three phase boundary (TPB) density and Ni network connectivity, is one of the main reasons of anode degradation. Thus, reliability and long time stability of the anode remains as the main challenge of the current SOFC research and development $[3,4,5,6,7,8,9,10,11]$. Manufacturing and reduction processes are of great importance to improve initial performance and long-term stability of the anode. Plascencia \& Utigard [12] and Utigard et al. [13] have studied the reduction process of $\mathrm{NiO}$ at different temperatures, and showed that different reduction temperatures lead to totally different morphologies of Ni particles, which may influence the initial performance and stability of Ni-YSZ composite anode. Jeangros et al. [14, 15] have conducted in-situ observation of $\mathrm{NiO}$ reduction process in $\mathrm{NiO}-\mathrm{YSZ}$ composite anode using an environmental transmission-electron-microscopy at low temperature bellow $500{ }^{\circ} \mathrm{C}$. It was reported that the reduction of $\mathrm{NiO}$ starts from at $\mathrm{NiO}-\mathrm{YSZ}$ interface at $380{ }^{\circ} \mathrm{C}$ and the $\mathrm{Ni}$ particle agglomeration and sintering were found to take place in the reduction process from a temperatures of $400{ }^{\circ} \mathrm{C}$. However, the hydrogen $\left(\mathrm{H}_{2}\right)$ pressure and operation temperature used for observation were both much lower than the real anode operation environment.

Zhu et. al. [16] have reported that the initial microstructure of Ni-YSZ and the corresponding performances can be influenced by the reduction and coarsening processes of $\mathrm{NiO}$ to $\mathrm{Ni}$. Jiao et al. [17] have quantitatively studied the correlation between Ni-YSZ anode performance and the reduction temperature based on three-dimensional (3D) focused ion beam-scanning electron microscopy (FIB-SEM) reconstruction. Ni-YSZ composite anodes were reduced at temperatures of $500{ }^{\circ} \mathrm{C}, 800{ }^{\circ} \mathrm{C}$ and $1000{ }^{\circ} \mathrm{C}$ and the corresponding electrochemical performances were measured in $3 \% \mathrm{H} 2 \mathrm{O}$ humidified $\mathrm{H}_{2}$ at $800{ }^{\circ} \mathrm{C}$. 
The microstructure changes for three cases before and after 100 hours operation have been quantitatively investigated by FIB-SEM. It was found that with the increase of reduction temperature, Ni-YSZ interfacial bonding can be enhanced, which inhibits the nickel sintering, and improves the anode performance stability in long-time operation. Performance of anode reduced at $1000{ }^{\circ} \mathrm{C}$ was even enhanced compared to the initial performance during the operation.

Ni-film anodes on YSZ has been recognized as a promising approach to determine the kinetics of electrochemical reactions for SOFC anode $[8,18]$. Compared to conventional Ni-YSZ cermet anode, the reaction zone can be well defined. However most of the previous researches were conducted based on Ni-film anode without high temperature sintering, which is also different from the situation in the conventional Ni-YSZ cermet anode. In this study, in order to further investigate the influences of reduction temperature on Ni-YSZ composite anode performance and stability, Ni-film anodes sintered on YSZ substrate at high temperature were used for the direct observation of Ni-YSZ interface with the same reduction and operation conditions as conventional Ni-YSZ composite anode. In addition, the simple design of anode also facilitates quantitative observation of $\mathrm{NiO}$ reduction and sintering by removing the influence from the constrain of the complicated YSZ skeleton microstructure.

\section{Experimental}

Ni-film anode preparation - Approximate $900 \mathrm{~nm}$-thick Ni film was fabricated by Ni sputtering method (CANON-ANELVA E-200S, 1 Pa, $300 \mathrm{~W}$, room temperature, argon) with an area of $1.0 \mathrm{~cm}^{2}$ on a YSZ pellet. Commercial dense $8 \mathrm{~mol} 3 \%$ YSZ pellet (diameter $24 \mathrm{~mm}$, thickness $0.5 \mathrm{~mm}$, Fine Ceramics Corp., Japan) was firstly polished by diamond paste to achieve a flat surface with roughness less than 0.1 microns. The Ni film and YSZ pellet were then co-sintered at $1450{ }^{\circ} \mathrm{C}$ for 3 hours to produce $\mathrm{NiO}$-film anode as conventional 
NiO-YSZ composite anode. The cathode material was prepared by printing Pt paste on the contour side of the YSZ pellet with the same size as the anode. The YSZ pellet was surrounded by a Pt wire as reference electrode. Pt paste was used to enhance the conductive connection between Pt wire and YSZ pellet [17].

Electrochemical evaluation - Three NiO-film anodes were reduced in $5 \%$ by nitrogen diluted $\mathrm{H}_{2}$ at $500{ }^{\circ} \mathrm{C}, 800{ }^{\circ} \mathrm{C}$ and $1000{ }^{\circ} \mathrm{C}$ for 75 minutes, 15 minutes and 1 minutes, respectively, to ensure a complete reduction. The environment temperatures of anodes reduced at $500{ }^{\circ} \mathrm{C}$ and $1000{ }^{\circ} \mathrm{C}$ were then changed to $800{ }^{\circ} \mathrm{C}$ with a continuous supply of pure $\mathrm{H}_{2}$ with a temperature ramping rate of $10{ }^{\circ} \mathrm{Cmin}^{-1}$. The performances of anodes were then evaluated at $800{ }^{\circ} \mathrm{C}$ with $3 \% \mathrm{H}_{2} \mathrm{O}$ humidified $\mathrm{H}_{2}$ as a fuel and pure oxygen as an oxidant (gas flowrates were $100 \mathrm{mlmin}^{-1}$ for both anode and cathode). Anode was operated with an anode-to-reference (A-R) voltage of $0.6 \mathrm{~V}$ and all the experiments have been repeated to ensure the reproducibility. For comparison, anode was also kept at open circuit voltage (OCV) for 100 hours to investigate the influence of $\mathrm{Ni}$ sintering on anode performance without electrochemical reactions. Electrochemical impedance spectroscopy (frequency range: $1-10^{5} \mathrm{~Hz}, \mathrm{AC}$ signal strength: $10 \mathrm{mV}$ ) measurements were conducted using Solatron frequency analyzer (1255WB) at OCV.

SEM observation - All the samples chosen for SEM observation were taken from the region close to the center of the anode after experiments. The samples were then polished using Ar-ion beam cross-section polisher (JEOL Ltd., SM09010) and observed by SEM with a magnification of 8000 .

\section{Experimental results}

The corresponding top surface and cross-sectional SEM images of original $\mathrm{Ni}$ film after sputtering and $\mathrm{NiO}$ film after sintering are shown in Fig. 1. The 
grain boundary of $\mathrm{NiO}$ after high temperature sintering can be observed with an average size of about 3 microns. Both Ni-film after sputtering and NiO-film after sintering are well-bonded with the YSZ substrate. Original YSZ surface after polishing is shown in the embedded frame in Fig. 1 (a). For the YSZ surface after Ni-YSZ co-sintering, $\mathrm{NiO}$ was removed by nitric acid after being reduced to Ni. It is shown in the embedded frame in Fig. 1 (b) that $\mathrm{NiO}$ crystal shape patterns were formed on YSZ surface after co-sintering.

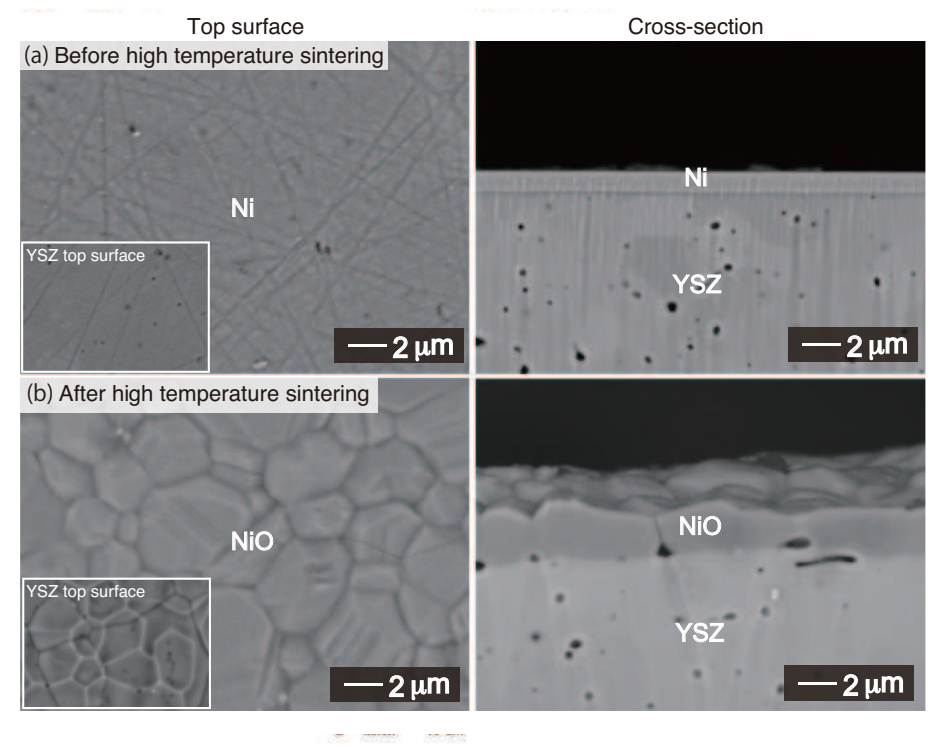

Figure 1: SEM images of top surface and cross-section of (a) original Ni film after sputtering and (b) NiO film after sintering.

The performances and durabilities of anodes reduced at $500{ }^{\circ} \mathrm{C}, 800{ }^{\circ} \mathrm{C}$ and $1000^{\circ} \mathrm{C}$ are shown in Fig. 2 with A-R voltage of $0.6 \mathrm{~V}$. It is seen that the anode reduced at $500{ }^{\circ} \mathrm{C}$ shows a high initial performance and a relatively high degradation rate in the initial 25 hours operation. The anode performance shows small fluctuation after about 40 hours operation, and the anode performance was slightly enhanced during the rest of the operation. For the anode reduced at $800{ }^{\circ} \mathrm{C}$, a lower initial performance is observed compared to the anode reduced 
at $500{ }^{\circ} \mathrm{C}$. The initial degradation rate decreased with time and entered a stable stage after about 20 hours operation with a very low degradation rate. For the anode reduced at $1000{ }^{\circ} \mathrm{C}$, the lowest initial performance is observed. The difference from the other two reduction temperature anodes is that no degradation is observed from the beginning to the end of the operation. All the pulse signals shown in the plots are attributed to the impedance spectra measurements.
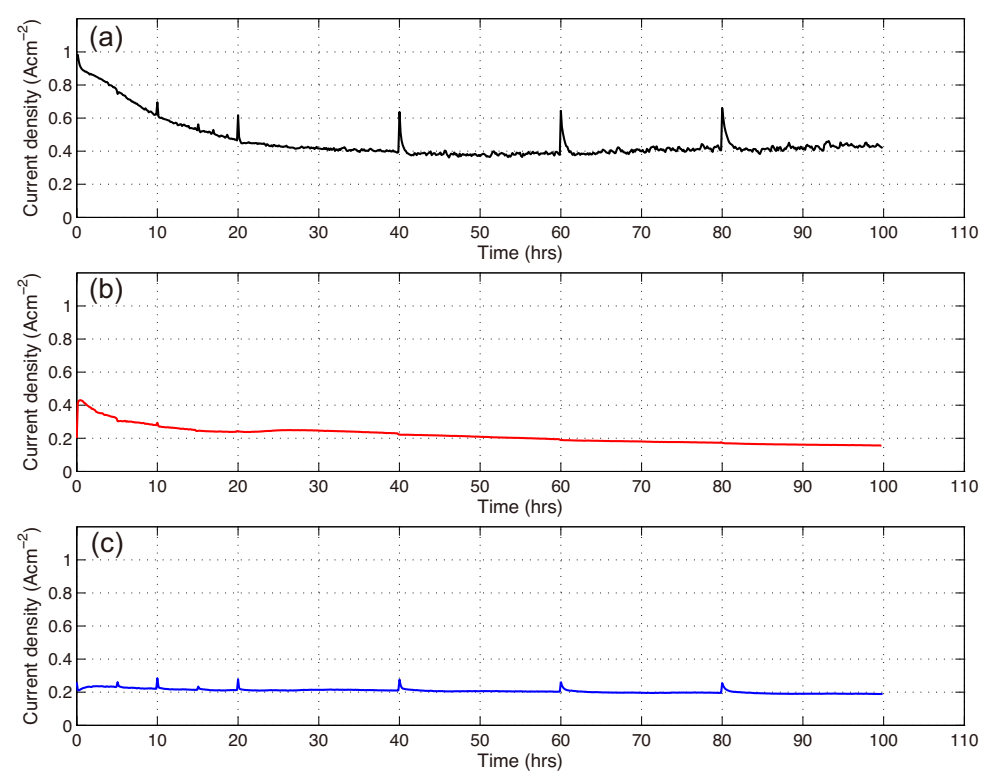

Figure 2: Ni-film electrode performances within 100 hours with $\mathrm{NiO}$ film reduced at (a) $500{ }^{\circ} \mathrm{C}$, (b) $800{ }^{\circ} \mathrm{C}$ and (c) $1000{ }^{\circ} \mathrm{C}$ (Anode-to-reference voltage, $0.6 \mathrm{~V}$ ).

The corresponding A-R impedance spectra changes against operation time in operation for three anodes are shown in Fig. 3 (a)-(c). It is seen that the ohmic resistances of anodes with three reduction temperature did not change, while the polarization resistances showed considerable changes. For the anode reduced at $500{ }^{\circ} \mathrm{C}$, the smallest initial polarization resistance corresponds to the highest initial performance. The rapid increase about 8 times in the initial 20 hours operation explains the initial high degradation rate of anode performance as shown in Fig. 2 (a). The polarization resistance then reduced by a 
certain mechanism until the end of the operation. For anode reduced at $800{ }^{\circ} \mathrm{C}$, the anode polarization resistance continuously increased during the whole operation time, but the increasing rate decreased after the initial 20 operation. For the anode reduced at $1000{ }^{\circ} \mathrm{C}$, polarization resistance slightly increased in the initial 20 hours and decreased with time in the rest of the operation. The final polarization resistance value became even smaller than the initial value. In order to quantitatively analyze the impedance spectra, an equivalent circuit model based on was built to calculate the corresponding electrochemical ohmic and polarization resistances, which has been introduced in Ref. [19]. The average polarization resistance degradation rates for the three anodes were about $2.1 \% \mathrm{~h}^{-1}, 3.9 \% \mathrm{~h}^{-1}$ and $-0.15 \% \mathrm{~h}^{-1}$, respectively. It is seen that the anode reduced at $1000{ }^{\circ} \mathrm{C}$ showed the most stable performance with performance enhanced during the operation. As shown in Fig. 3, it can be expected that anode reduced at $1000{ }^{\circ} \mathrm{C}$ shows better stability than the other two anodes in a longer time operation.
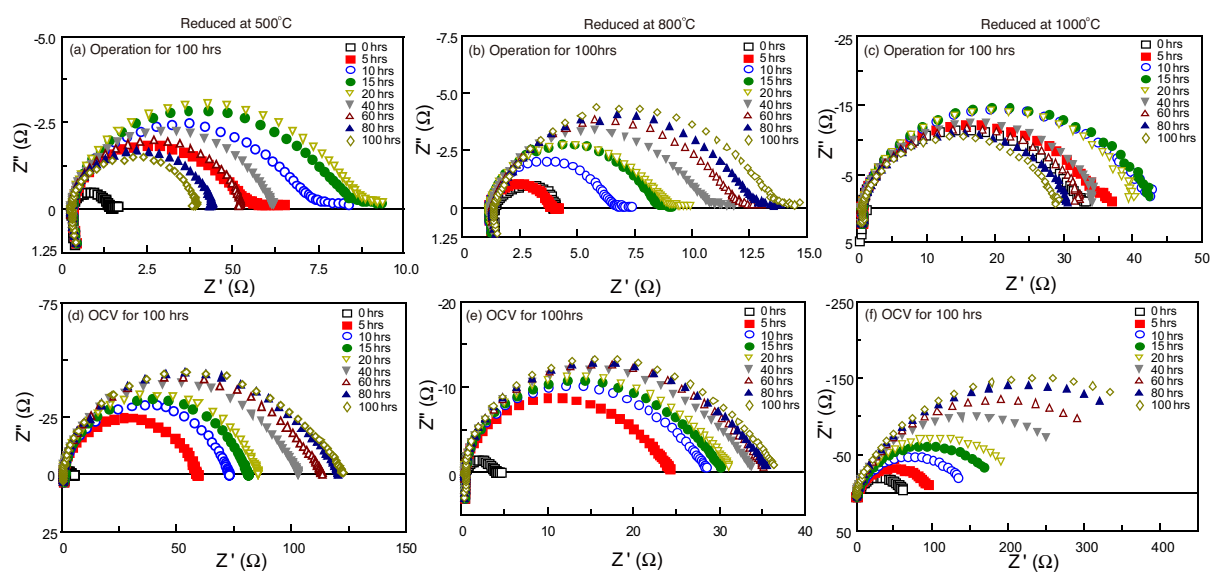

Figure 3: A-R impedance spectra against time after being kept at (a)(b)(c) operation and (d)(e)(f) OCV for 100 hrs with three different reduction temperatures.

For the experiment of being kept at OCV for 100 hours, the polarization resistances of the three anodes reduced at $500{ }^{\circ} \mathrm{C}, 800{ }^{\circ} \mathrm{C}$ and $1000{ }^{\circ} \mathrm{C}$ showed 
continuous degradation with average degradation rates of about $25.0 \% \mathrm{~h}^{-1}$, $6.9 \% \mathrm{~h}^{-1}$ and $5.0 \% \mathrm{~h}^{-1}$, respectively. It is found that polarization resistance degradation rates change from large to small or start to decrease reversely at about 20 hours for all the cases as shown in Fig. 3 (a)-(f).

Figures 4, 5 and 6 show the SEM images of both cross-sections and top surfaces of NiO-film anodes reduced at $500{ }^{\circ} \mathrm{C}, 800{ }^{\circ} \mathrm{C}$ and $1000{ }^{\circ} \mathrm{C}$, respectively. The material can be identified by the contrast difference, where gray color indicates $\mathrm{Ni}$ and YSZ, and dark gray color indicates $\mathrm{NiO}$ [17]. When the anode was reduced at $500{ }^{\circ} \mathrm{C}$, no obvious microstructure change can be observed for the initial 30 minutes as shown in Fig. 4 (a). A small amount of sub-micron-scale pores were formed along the $\mathrm{NiO}$ grain boundary and NiO-YSZ interface. Very few sub-micron-scale pores were formed on $\mathrm{NiO}$ crystal surface. After 60 minutes reduction, more sub-micron-scale pores formed on $\mathrm{NiO}$ crystal surface are observed, while $\mathrm{NiO}$ along the grain boundary was reduced by a certain depth. Some discontinuous gaps were formed along the NiO-YSZ interface. After 75 minutes reduction, $\mathrm{NiO}$ was completely reduced to $\mathrm{Ni}$ with $40 \%$ volume reduction, which was achieved by the formation of large amount of sub-micron-scale inner pores uniformly distributed in the Ni phase. The peripheral shape of the newly formed Ni phase nearly kept the original morphology of the $\mathrm{NiO}$ and the $\mathrm{Ni}$ grains were separated from each other by gaps formed along the $\mathrm{NiO}$ grain boundary. Original NiO-YSZ interface was almost destructed by continuous gaps formed between reduced Ni and YSZ surface with only very few points remained bonded. An average NiO-Ni conversion rate of about $1.3 \% \mathrm{~min}^{-1}$ was observed while the real-time reduction rate was obviously accelerated after the initial 60 minutes reduction.

For the anode reduced at $800{ }^{\circ} \mathrm{C}$, relatively dense $\mathrm{Ni}$ layer was formed in the initial 20 seconds reduction. The volume reduction in NiO-Ni transformation was achieved by the densification of Ni. Non-continuous gaps are observed between Ni and YSZ. The gaps formed during the reduction process along $\mathrm{NiO}$ 

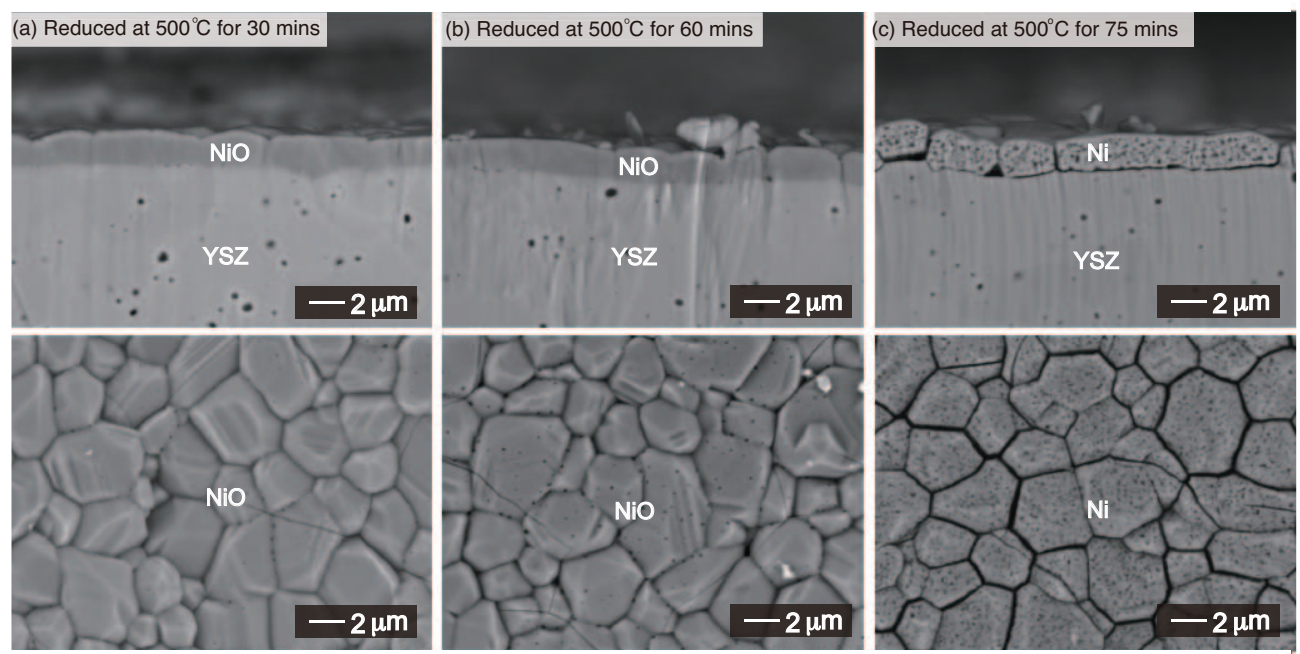

Figure 4: Cross-sectional and top SEM images of NiO-film electrode reduced at $500{ }^{\circ} \mathrm{C}$ for (a) 30 mins, (b) 60 mins and (c) 75 mins.
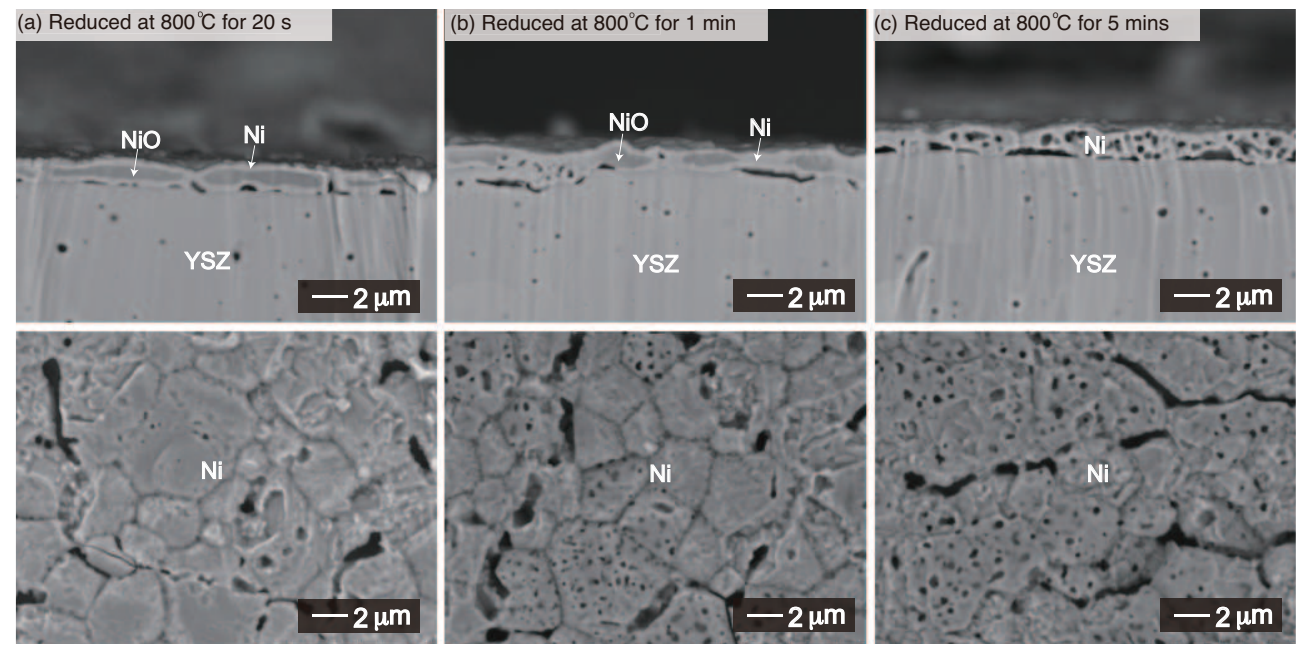

Figure 5: Cross-sectional and top SEM images of NiO-film electrode reduced at $800{ }^{\circ} \mathrm{C}$ for (a) $20 \mathrm{~s}$, (b) 1 min and (c) 5 mins. 

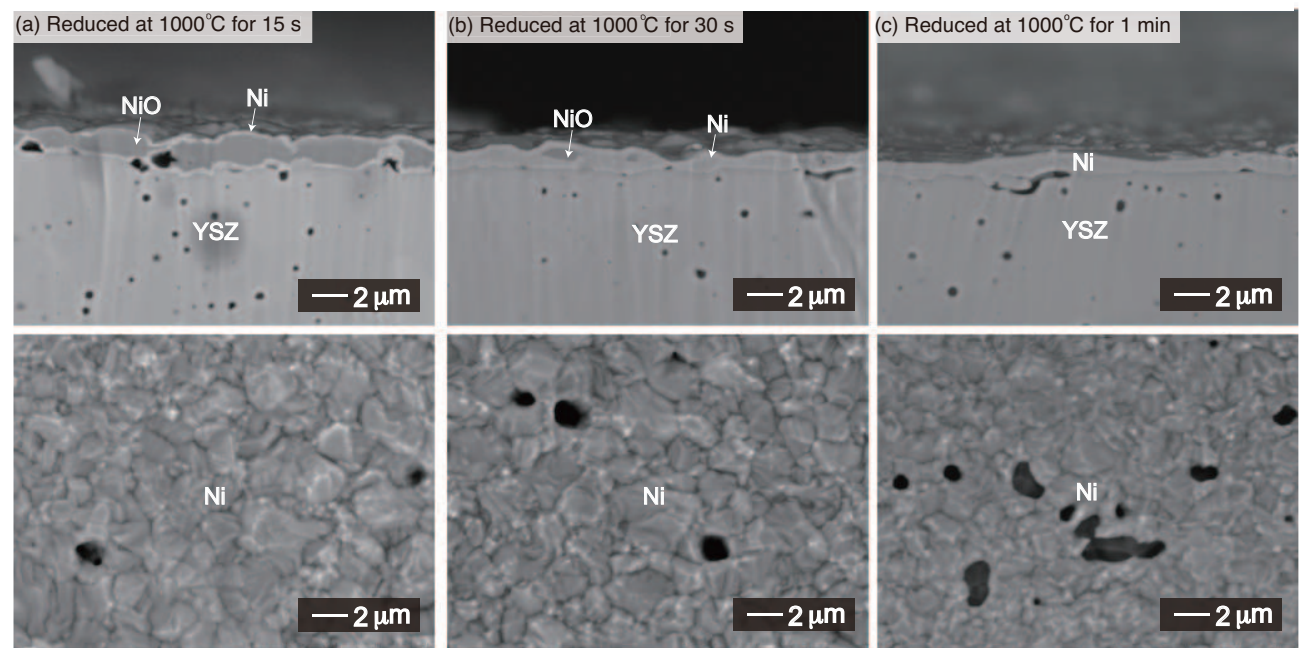

Figure 6: Cross-sectional and top SEM images of NiO-film electrode reduced at $1000{ }^{\circ} \mathrm{C}$ for (a) $15 \mathrm{~s}$, (b) $30 \mathrm{~s}$ and (c) $1 \mathrm{~min}$.

grain boundary were partially healed and enlarged by non-uniform Ni sintering, and the initial $\mathrm{NiO}$ morphology was largely modified. After 1 minute reduction, certain amount of inner pores formed in newly reduced Ni phase, and the reduction rate obviously slowed down compared to the initial 20 seconds. After 5 minutes reduction, $\mathrm{NiO}$ was completely reduced to $\mathrm{Ni}$ with micron-size inner pores formed inside. The initial morphology of $\mathrm{NiO}$ was completely changed. The contact between $\mathrm{Ni}$ and YSZ remained at certain contacting areas. An average NiO-Ni conversion rate of about $20.0 \% \mathrm{~min}^{-1}$ was observed. , and a deceleration of reduction rate was observed after the initial 1 minute reduction.

When the anode was reduced at $1000{ }^{\circ} \mathrm{C}$, dense $\mathrm{Ni}$ was formed throughout the reduction process. The reduction completed after 1 minute and the Ni phase was well-bonded to the YSZ surface with certain large pores formed along NiYSZ interface. Morphology of newly reduced Ni was completely different from the original $\mathrm{NiO}$ phase and certain large pores were also formed on $\mathrm{Ni}$ surface along $\mathrm{Ni}$ crystal grain boundary. An average NiO-Ni conversion rate of about 
$100.0 \% \mathrm{~min}^{-1}$ was observed without obvious acceleration and deceleration of reduction rate.

After the initial 1 hour reduction of anode at $500{ }^{\circ} \mathrm{C}$, the newly formed porous Ni with very large specific surface area and caused the acceleration of reduction in the last 15 minutes. For $800{ }^{\circ} \mathrm{C}$ reduction, the initially formed dense Ni layer may prohibite the gas diffusion and decelerated the final reduction rate. For $1000{ }^{\circ} \mathrm{C}$ case, although very dense Ni layer was formed initially, obvious deceleration of reduction rate was not observed. Similar phenomenon has been reported by Utigard et al. [13]. Based on the observations at different temperatures, it was also found that the reduction rates at Ni-pore and Ni-YSZ interfaces were the same for all three cases.

Figure 7 (a)-(c) and Fig. 8 (a)-(c) show the comparisons of interface crosssections and top-surfaces of anodes being operated for 100 hours. In contrast to the Ni-YSZ interfaces right after reduction at $500{ }^{\circ} \mathrm{C}$ and $800{ }^{\circ} \mathrm{C}$, it is seen that most of the inner pores in $\mathrm{Ni}$ were eliminated by $\mathrm{Ni}$ sintering. The gaps formed between Ni and YSZ were partially healed by certain mechanism. For the anode reduced at $500{ }^{\circ} \mathrm{C}$, as shown in Fig. 8 (a), certain amount of sub-micron-scale roughness can be observed on the YSZ surface compared to the initial smooth YSZ surface as shown in the embedded frame in Fig. 1 (b). For the anode reduced at $1000{ }^{\circ} \mathrm{C}$, Ni nearly remained the original densified state after reduction and kept well-bonded with YSZ surface as shown in Fig. 7 (c). Based on the observation of the top-surfaces of three anodes, it is clearly seen that $\mathrm{Ni}$ sintering caused obvious $\mathrm{Ni}$ crystal grain growth and obvious modification of the original Ni surface morphologies. Figure 7 (d)-(f) and Fig. 8 (d)-(f) show the comparisons of Ni-YSZ interface cross-sections and top surfaces of anodes being kept at OCV for 100 hours. As shown in Fig. 7 (d), it is seen that most of the sub-micron-scale inner pores formed in $\mathrm{Ni}$ reduced at $500{ }^{\circ} \mathrm{C}$ aggregated into micron-scale ones, while the continuous gap between Ni and YSZ remained the same as the initial reduction state $(4(\mathrm{c}))$. No gap-healing phenomenon is 
observed at Ni-YSZ interface, and gaps formed along the original $\mathrm{NiO}$ grain boundary remained. For the anode reduced at $800{ }^{\circ} \mathrm{C}$, no sub-micron-scale inner pores were observed in $\mathrm{Ni}$ and the gaps formed along original $\mathrm{NiO}$ grain boundary remained in certain extent without being healed. Ni remained partially bonded to YSZ surface without being enhanced. For the anode reduced at $1000{ }^{\circ} \mathrm{C}$, Ni remained the original densified state and kept well-bonded with YSZ surface. Based on the observations of Ni densification and grain-growth, it is clearly seen that $\mathrm{Ni}$ sintering in the anode being operated was obviously enhanced compared to the anode being kept at OCV. It is seen that discharge in operation enhances $\mathrm{Ni}$ sintering, Ni-YSZ gap-healing phenomenon and the morphological change of YSZ surface.
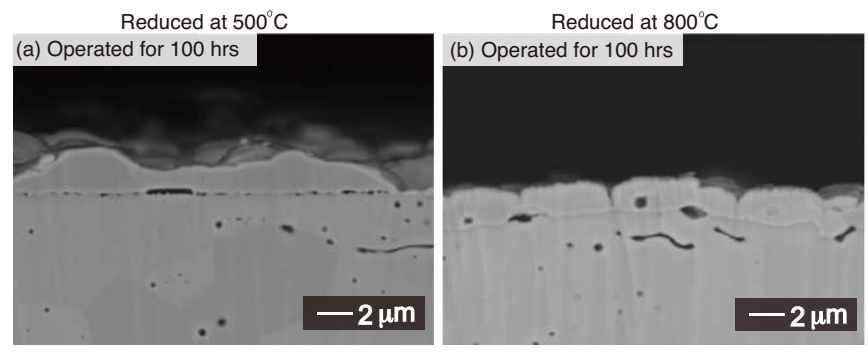

Reduced at $1000^{\circ} \mathrm{C}$ 

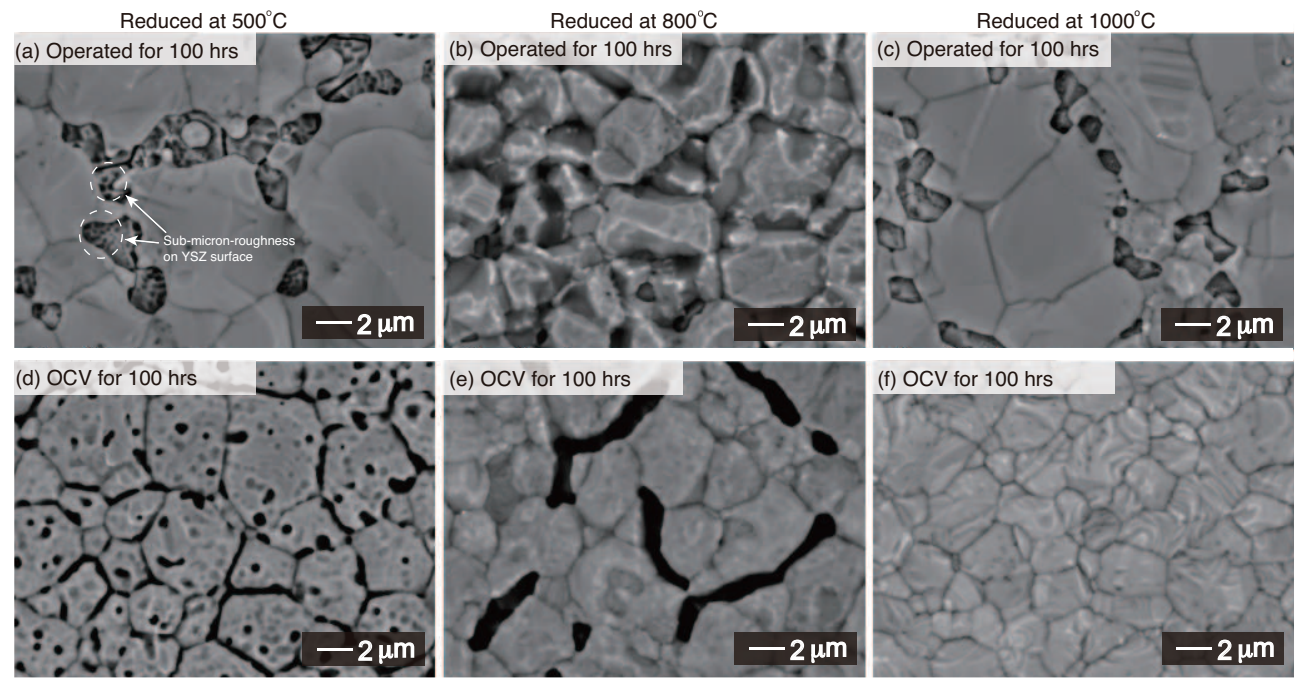

(f) OCV for 100 hrs

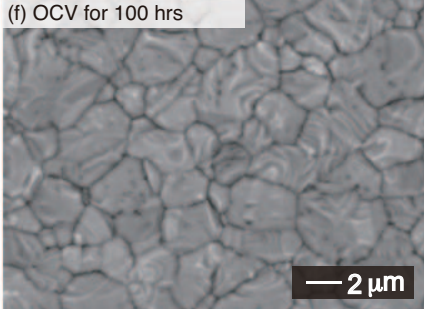

Figure 8: Top-surface SEM images of NiO-film electrode after being kept at operation and OCV for 100 hours with different reduction temperatures of $500{ }^{\circ} \mathrm{C}, 800{ }^{\circ} \mathrm{C}$ and $1000{ }^{\circ} \mathrm{C}$ corresponding to Fig. 3.

\section{Discussions}

Based on the experimental results, it is seen that the reduction temperature obviously influences the initial microstructure of Ni and Ni-YSZ interface which leads to different initial performances and stabilities in long-time operation. The reduction process is determined by the competition between $\mathrm{NiO}-\mathrm{Ni}$ transfer volume reduction and $\mathrm{Ni}$ sintering mechanisms at the same time. In a low temperature reduction process, such as $500{ }^{\circ} \mathrm{C}$, the reduction process is dominated by the volume reduction mechanism. Reduced Ni keeps the original morphology of $\mathrm{NiO}$ with large amount of sub-micron-scale pores formed inside $\mathrm{Ni}$ and along Ni-YSZ interface. The sub-micron-scale pores along Ni-YSZ interface lead to the enhancement of active TPB so that the initial performance, which explains the highest initial discharge current density during operation as shown in Fig. 3 (a). At the same time, the large amount of pores along Ni-YSZ interface weaken the Ni and YSZ bonding and enhances Ni sintering due to its very high surface energy together with the large amount of inner pores of Ni. 
The combination of two effects may explain the high degradation rate in the initial 25 hours. Performance enhancement observed in the experiment can be attributed to the healing of gaps between $\mathrm{Ni}$ and YSZ during operation with discharge. Ni spreading phenomenon along active TPB in operation has been reported in our previous research which is caused by the vaporization-deposition mechanism of $\mathrm{Ni}(\mathrm{OH})_{2}$ driven by the outward humidity gradient from TPB to bulk gas environment [20]. The spreading of Ni may gradually and partially heal the gaps between Ni and YSZ during the 100 hours operation. The healing effect at the same time may increase the local active TPB density and enhance the anode performance. The sub-micron-scale roughness formed on YSZ surface might be attributed to the cubic-tetragonal YSZ crystal structure transformation with discharge in operation, while similar phenomenon has been reported previously [21]. It has been reported by Coors et al. and Shimonosono et al. $[22,23]$ that the conductivity of YSZ containing dissolved $\mathrm{Ni}$ as a result of co-sintering in air with $\mathrm{NiO}$ gradually decreased during exposure to a hydrogen containing atmosphere in high temperature because of the cubic-tetragonal transformation. The YSZ crystal structure transformation thus may explain the initial degradation for all three Ni-film anodes before 20 hours with polarization resistances increased with operation time [1]. The competition between negative effect of Ni sintering and the positive effect of gap-healing phenomenon finally determine the anode performance as shown in Fig. 3 (a). Although the anode performance can be reversely enhanced after the initial degradation, the anode performance became unstable in the rest of the operation. It can be predicted that in a long-time operation, the enhanced sintering of Ni may also cause negative influence on the conventional Ni-YSZ composite anode performance, which has been reported by previously [17].

For high reduction temperature, such as at $1000{ }^{\circ} \mathrm{C}$, the reduction process is dominated by $\mathrm{Ni}$ sintering. Original morphology of $\mathrm{NiO}$ can be modified by the rapid sintering of reduced Ni. The sintering of Ni can also eliminate the inner pores formed with a volume reduction $[14,20]$ and lead to the formation of 
dense Ni. It has been reported by Howe [24] that a high temperature increases interaction across a metal-ceramic interface by increasing the mobilities of both atoms and dislocations. Thus, when $\mathrm{NiO}$ is reduced at $1000{ }^{\circ} \mathrm{C}$, a well-bonded Ni-YSZ interface can be formed and the best stability of anode during operation is achieved as shown in Fig. 3 (c). The tight bonding between Ni and YSZ resulted in a much lower TPB density compared to the anode reduced at $500{ }^{\circ} \mathrm{C}$, which may explain the largest polarization resistance and the corresponding lowest initial performance. The performance enhancement phenomenon during operation can also be attributed to the $\mathrm{Ni}$ spreading phenomenon along active TPB [20]. At the same time, the enlarged pores formed in dense Ni phase may also contribute to the performance enhancement by enlarging the TPB density as shown in the comparison between Fig. 7 (c) and Fig. 8 (c).

Compared to the other two reduction temperatures, reduction at $800{ }^{\circ} \mathrm{C}$ leads to an intermediate status for both Ni sintering and Ni-YSZ interface bonding. The reduction process was not dominated by a single mechanism but the combination of volume reduction and Ni sintering mechanisms. After 100 hours operation, Ni-YSZ interface bonding was enhanced clearly as the case for $500{ }^{\circ} \mathrm{C}$ reduction at. Part of Ni-YSZ interface remained well-bonded and delamination of Ni from YSZ surface was not observed even when it was kept at OCV for 100 hours. The performance enhancement was not observed in operation as shown in Fig. 3 (b), which might be due to the limited operation time. It is seen that the polarization resistance increases very little in the last 40 hour operation and the performance enhancement might be observed if the operation is extended to a longer time.

Based on the above discussions, it can be concluded that a lower temperature reduction leads to a higher initial performance according to larger TPB density and more unstable Ni-YSZ interface according to the weak Ni-YSZ bonding. The higher initial performance can degrade rapidly because of the weak Ni-YSZ bonding and the enhanced $\mathrm{Ni}$ sintering attributed to very porous $\mathrm{Ni}$ formed in 
lower temperature reduction. A higher reduction temperature results in a lower initial performance according to smaller TPB density and more stable Ni-YSZ interface according to the strong Ni-YSZ bonding. The comparison between Figs. 3 (a)-(c) and (d)-(f) shows that the negative effect of Ni sintering on anode stability can be partially compensated by the healing effect caused by discharge in operation. The discharge at the same time enhances Ni sintering due to higher local humidity generated in electrochemical reactions [20]. Nifilm anode is much less durable than the conventional Ni-YSZ composite anode, since there is no YSZ skeleton to constrain Ni coarsening. At the same time, the morphological change of $\mathrm{Ni}$ phase without the constrain from YSZ skeleton facilitate the observation of Ni-YSZ interface and the conclusions also support with the phenomena observed in the experiments of conventional composite NiYSZ anode with different reduction temperatures, as reported previously by Jiao et al. [17]. Thus, in practical application, a higher reduction temperature should be used to improve the anode long-term stability. Although the initial performance is lower than the cases with a lower reduction temperatures, the anode can achieve a better performance in a long-time scale [17]. In the future, the quantitative reduction rate information obtained in this study can also be introduced into the numerical simulation of the reduction process in SOFC anode [25].

\section{Conclusions}

In this study, NiO-film anodes were fabricated by sintering Ni-film anodes at $1450{ }^{\circ} \mathrm{C}$ and reduced at $500{ }^{\circ} \mathrm{C}, 800{ }^{\circ} \mathrm{C}$ and $1000{ }^{\circ} \mathrm{C}$ to investigate the influences of reduction temperature on the performance and stability of Ni-YSZ anode. It is found that the reduction process of $\mathrm{NiO}$ is determined by the competition between the volume reduction in $\mathrm{NiO}-\mathrm{Ni}$ transformation and $\mathrm{Ni}$ sintering. In a low temperature reduction, the reduction process is dominated by the volume reduction mechanism in NiO-Ni transfer while $\mathrm{Ni}$ tends to be very porous and weakly 
bonded to the YSZ surface. In a high temperature reduction, the reduction process is dominated by Ni sintering, and dense Ni and strong Ni-YSZ bonding can be formed. The anode performances and microstructural changes before and after 100 hours operation and OCV operations were also investigated. The anode reduced at $500{ }^{\circ} \mathrm{C}$ showed the highest initial performance but the lowest stability. Anode reduced at $1000{ }^{\circ} \mathrm{C}$ showed the most stable performance but the lowest initial performance. It is seen that the increase of reduction temperature leads to the improvement of anode stability during long-time operation. It is considered that the degradation of anode is determined by the competition of Ni sintering and the change of Ni-YSZ interface bonding strength. At the same time, both Ni sintering and Ni-YSZ interface bonding strength can be enhanced by discharge current in operation which can be attributed to the local humidity generated in electrochemical reactions.

\section{Acknowledgments}

This work was partly supported by the Core Research for Evolution Science and Technology (CREST), JST, Japan.

\section{Reference}

\section{References}

[1] C.S. Subhash, K. Kevin, High Temperature Solid Oxide Fuel Cells: Fundamentals, Design and Applications, Elsevier Advanced Technology, 2003.

[2] S. Primdahl, Ph.D. Thesis, Riso National Laboratory for Sustainable Energy, Technical University of Denmark, Denmark, 1999.

[3] L. Holzer, B. Munch, B. Iwanschitz, M. Cantoni, T. Hocker, T. Graule, Quantitative relationships between composition, particle size, triple phase boundary length and surface area in nickel-cermet anodes for Solid Oxide Fuel Cells, J. Power Sources 196 (2011) 7076-7089. 
[4] S.P.S. Badwal, M.J. Bannister, R.H.J. Hannink, Science and Technology of Zirconia V, Technomic publishing Company, 2003.

[5] S. Koch, P.V. Hendriksen, M. Mogensen, Y-L. Liu, N. Dekker, B. Rietveld, B.De. Haart, F. Tietz, You have full text access to this content Solid Oxide Fuel Cell Performance under Severe Operating Conditions, Fuel Cells 2 (2006) 130-136.

[6] T. Matsui, J-Y. Kim, R. Kishida, K. Eguchi, Sudden Deterioration in Performance during Discharge of Anode-supported Solid Oxide Fuel Cells, Electrochemistry 77 (2009) 123-126.

[7] B. de Boer, Hydrogen oxidation at porous nickel and nickel/yttria- stabilised zirconia cermet electrodes, Ph.D. Thesis, University of Twente, the Netherlands, (1998).

[8] J. Mizusaki, H. Tagawa, T. Saito, T. Yamamura, K. Kamitani, K. Hirano, S. Ehara, T. Takagi, T. Hikita, M. Ippommatsu, S. Nakagawa, K. Hashimoto, Kinetic studies of the reaction at the nickel pattern electrode on YSZ in $\mathrm{H}_{2}-\mathrm{H}_{2} \mathrm{O}$ atmospheres, Solid State Ionics 70-71 (1994) 52-58.

[9] J. Mizusaki, H. Tagawa, T. Saito, T. Yamamura, K. Kamitani, K. Hirano, S. Ehara, T. Takagi, T. Hikita, M. Ippommatsu, S. Nakagawa, K. Hashimoto, Preparation of Nickel Pattern Electrodes on YSZ and Their Electrochemical Properties in $\mathrm{H}_{2}-\mathrm{H}_{2} \mathrm{O}$ Atmospheres, J. Electrochem. Soc. 141 (1994) 2129-2134.

[10] M.S. Schmidt, K.V. Hansen, K. Norrman, M. Mogensen, Three-phaseboundary dynamics at the Ni/ScYSZ interface, Solid State Ionics 180 (2009) 431-438.

[11] D. Simwonis, F. Tietz, D. Stover, Nickel coarsening in annealed Ni/8YSZ anode substrates for solid oxide fuel cells, Solid State Ionics 132 (2000) $241-251$. 
[12] G. Plascencia, T. Utigard, The reduction of Tokyo and Sinter 75 nickel oxides with $\mathrm{H}_{2}$, Chem. Eng. Sci. 64 (2009) 3879-3888.

[13] T. Utigard, M. Wu, G. Plascencia, T. Marin, Reduction kinetics of Goro nickel oxide using $\mathrm{H}_{2}$, Chem. Eng. Sci. 60 (2005) 2061-2068.

[14] Q. Jeangros, A. Faes, J.B. Wagner, T.W. Hansen, U. Aschauer, J.Van herle, A. Hessler-Wyser, R. E. Dunin-Borkowski, In situ redox cycle of a nickelYSZ fuel cell anode in an environmental transmission electron microscope, Acta. Materialia. 58 (2010) 4578-4589.

[15] Q. Jeangros, T.W. Hansen, J.B. Wagner, C.D. Damsgaard, R.E. DuninBorkowski, C. Hebert, J.Van herle, A. Hessler-Wyser, Reduction of nickel oxide particles by $\mathrm{H}_{2}$ studied in an environmental TEM, J. Mater. Sci. 48 (2012) 2893-2907 (2012).

[16] X. Zhu, C. Guan, Z. Lu, W. Su, Effects of Initial Reduction Temperature on the Microstructures and Performances of Ni/YSZ Anodes for Solid Oxide Fuel Cells, J. Electrochem. Soc. 160 (2013) F1170-F1174.

[17] Z. Jiao, N. Shikazono, Quantitative Study on the Correlation between Solid Oxide Fuel Cell Ni-YSZ Composite Anode Performance and Reduction Temperature Based on Three-Dimensional Reconstruction, J. Electrochem. Soc. 162 (6) (2015) F571-F578.

[18] A. Utz, H. Stormer, A. Leonide, A. Weber, E. Ivers-Tiffee, Degradation and Relaxation Effects of Ni Patterned Anodes in $\mathrm{H}_{2}-\mathrm{H}_{2} \mathrm{O}$ Atmosphere, J. Electrochem. Soc. 157 (2010) B920-B930.

[19] Z. Jiao, G.Lee, N. Shikazono, N. Kasagi, Quantitative Study on the Correlation Between Solid Oxide Fuel Cell Ni-YSZ Composite Anode Performance and Sintering Temperature Based on Three-dimensional Reconstruction, J. Electrochem. Soc 159 (2012) F278-F286. 
[20] Z. Jiao, N. Takagi, N. Shikazono, N. Kasagi, Study on local morphological changes of nickel in solid oxide fuel cell anode using porous $\mathrm{Ni}$ pellet electrode, J. Power Sources 196 (2011) 1019-1029.

[21] Z. Jiao, N. Shikazono, N. Kasagi, Study on degradation of solid oxide fuel cell anode by using pure nickel electrode, J. Power Sources 196 (2011) 8366-8376.

[22] W.G. Coors, J.R. O'Brien, J.T. White, Conductivity degradation of NiOcontaining 8YSZ and 10YSZ electrolyte during reduction, Solid State Ionics 180 (2009) 246-251.

[23] T. Shimonosono, H. Kishimoto, M. E. Brito, K. Yamaji, T. Horita, H. Yokokawa, Phase transformation related electrical conductivity degradation of NiO doped YSZ, Solid State Ionics 225 (2012) 69-72.

[24] J.M. Howe, Bonding structure, and properties of metal/ceramic interfaces: Part 1 Chemical bonding, chemical reaction, and interfacial structure, Int. Mater. Rev. 38 (1993) 233.

[25] Z. Jiao, N. Shikazono, Simulation of the reduction process of solid oxide fuel cell composite anode based on phase field method, J. Power Sources 305 (2016) 10-16. 